\title{
Evaluation of structural parameters of two Cylinder Crankshaft using finite element method
}

\author{
Ravikumar Katti \\ Department of Machine Design \\ Akshaya Institute of Technology, Tumakuru, Karnataka, India \\ Affiliated to Visvesvaraya Technological University, Belagavi \\ Praveen D N \\ BE., M.Tech., \\ Akshaya Institute of Technology, Tumakuru, Karnataka, India \\ Affiliated to Visvesvaraya Technological University, Belagavi \\ Lohitesh jaga Kumar \\ BE., M.Tech, M.I.S.I.T.E. \\ Akshaya Institute of Technology, Tumakuru, Karnataka, India \\ Affiliated to Visvesvaraya Technological University, Belagavi \\ Vijayavithal M Illal \\ BE., M.Tech \\ Sambhram institute of technology, Bangalore, Karnataka, India \\ Affiliated to Visvesvaraya Technological University, Belagavi
}

\begin{abstract}
Crankshafts are complex geometrical components which convert reciprocating motion into rotary motion, meanwhile the crankshaft encounters the bulk number of cyclic loads throughout its operation over a period the life of this component and fatigue performance can be considered during the design process. Design and optimization stages are very important in crankshaft production industries in order to minimize the failures and weight by considering proper optimization studies. These results lead lighter and smaller engines with superior fuel efficiency and high power generation on the engine.
\end{abstract}

In this paper, two cylinder crankshaft using forged steel is designed \& analyzed using Simulation software for agreeable results.

\section{INTRODUCTION}

Crankshaft experiences huge forces during combustion and expansion strokes in internal combustion engines. These forces act on the top of the piston which is connected to connecting rod and crankshaft, i.e. 
the force is transfer from piston to crank shaft. The magnitude and direction of these forces mainly determined by on many criteria's which consists of piston, connecting rod dimensions, crank radius and piston rings. The combustion and sudden forces produces bending and torsional loadings on the crankshaft, there are many sources of failures of the crank shaft during its operation those are grouped as operating, and mechanical design sources. One of the main sources of failure is fatigue. Fatigue is a variable load which acts on the crankshaft and which serves to fail at the fillet regions or at the regions of variable sections, due to this fatigue loading (combined torsional and bending) the crankshaft experiences large stresses at the fillet regions these stresses leads to initiate the surface cracks and leads to propagate until the catastrophic failure of fracture. The fatigue loadings are main important in the evaluation of life of the crank shaft

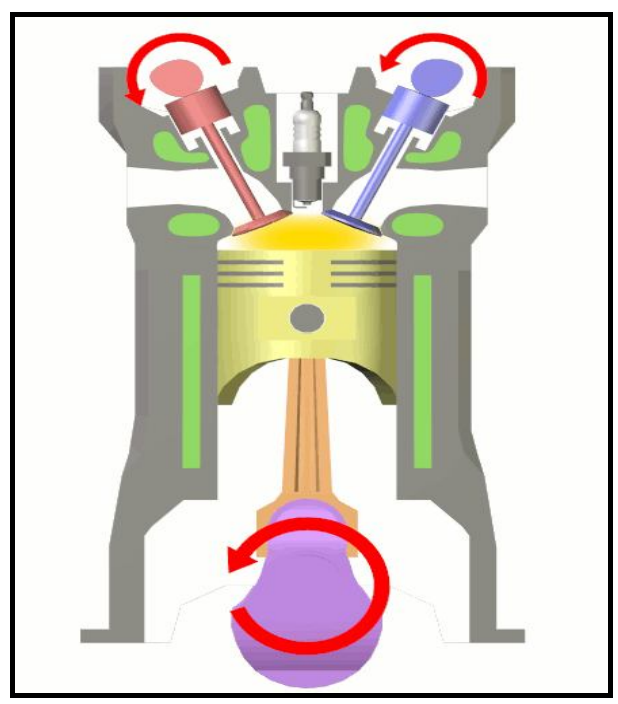

Figure 1. Typical crankshaft

The rest of the paper is organized as follows. Proposed theoretical calculation of body, wedge are explained in section II. Experimental results are presented in section III. Concluding remarks are given in section IV.

\section{PROPOSED THEORITCAL CALCULATION OF GATE VALVE}

\section{A. Crankshaft Body -}

In this case we are going to determine theoretical shell thickness calculation of crankshaft body. And also determine the Von-misses stress and find factor of safety. 


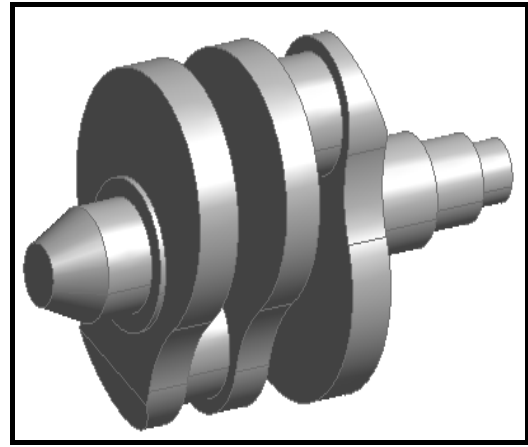

(a)

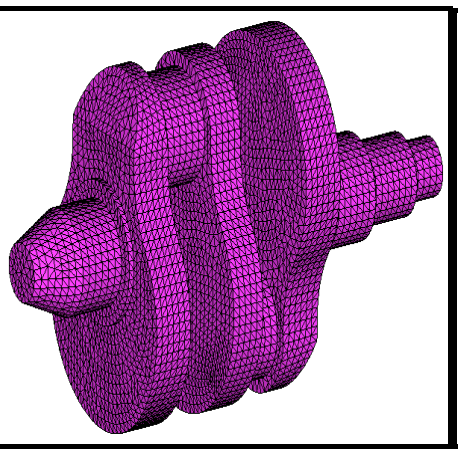

(b)

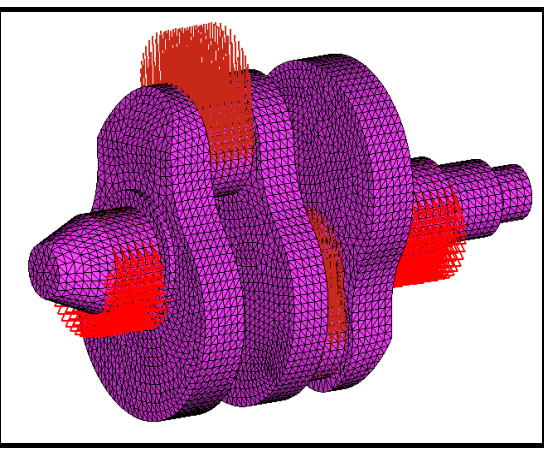

(c)

Figure2. (a)Crankshaft Body (b)Mesh model (c) Boundary condition

B. Valve specification -

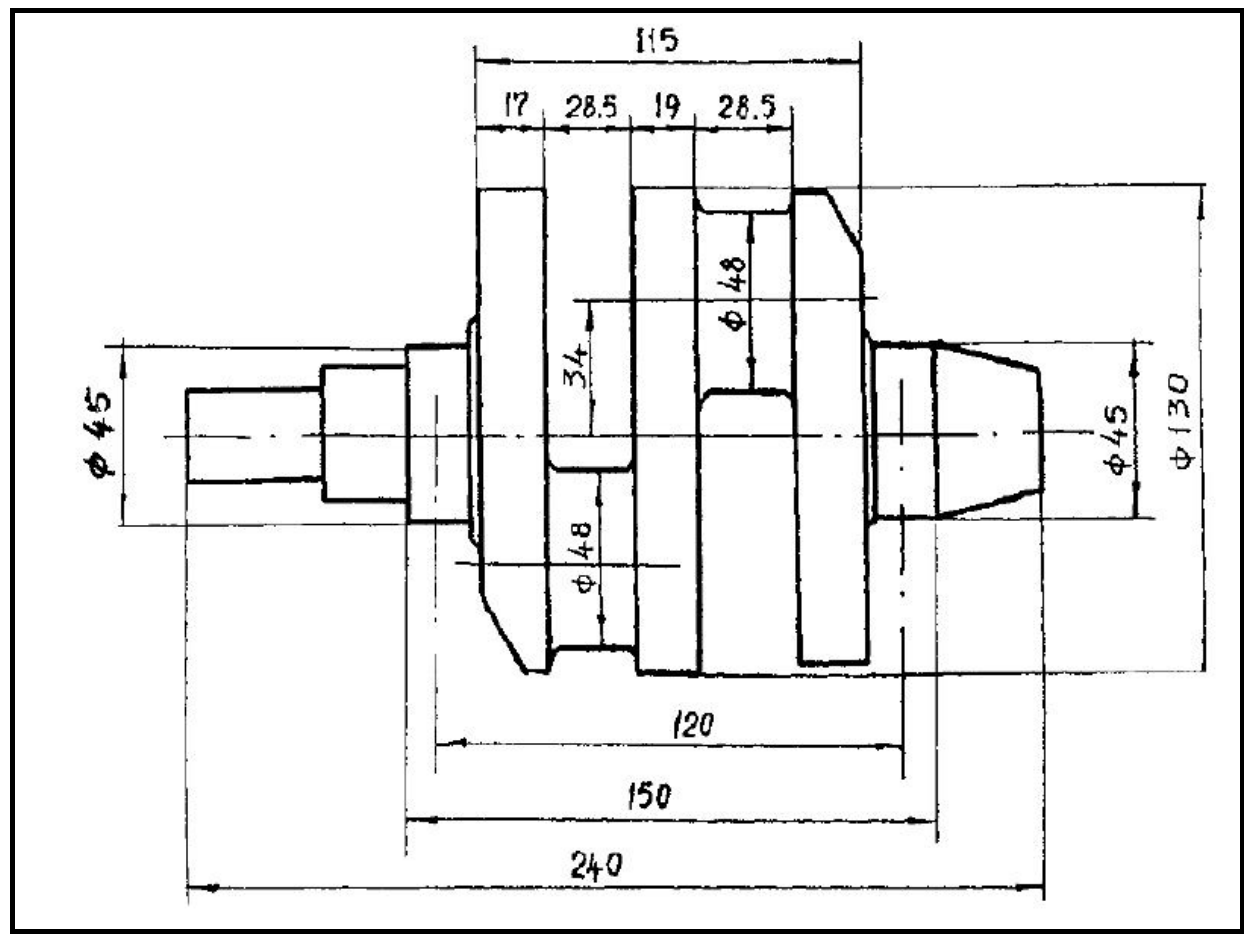

Figure 3. 2D view of two cylinder crankshaft 


\begin{tabular}{|l|l|}
\hline Crank pin radius & 22.6 \\
\hline Shaft Diameter & 34.925 \\
\hline Thickness of the Crank web & 21.336 \\
\hline Bore diameter & 53.73 \\
\hline Length of the crank pin & 43.6 \\
\hline Maximum pressure & 35 bar \\
\hline
\end{tabular}

Figure 4. Measurements of crankshaft

C. Force calculation -

$\rightarrow$ We know that

$$
\begin{aligned}
& F=P \times A \\
& \text { Where } A=\stackrel{\frac{\pi}{4}}{=} \times d 2 \quad \text { where } d=\text { diameter of crank i.e } \\
& P=157.619 \mathrm{bar} \\
& =157.619 \times 105 \mathrm{~N} / \mathrm{mm} 2 \\
& P=15.761 \times 106 \mathrm{~N} / \mathrm{mm} 2
\end{aligned}
$$$$
\text { Now } F=157.619 \times 105 \times 0.78(0.045) 2
$$$$
F p=25.07 \mathrm{KN}
$$

Therefore Force acting on the piston $F p=25.07 \mathrm{KN}$

$\rightarrow$ Have to calculate thrust force which is acting on the connecting rod.

$$
\begin{aligned}
& \sin \phi=\frac{\sin \theta}{L / R} \\
& \text { Where }^{\theta}=\text { angle of inclination (15.710) } \\
& \emptyset=\text { angle of inclination between connecting rod and stroke } \\
& L=265 \mathrm{~mm} \quad R=22.5 \mathrm{~mm} \\
& \sin ^{\emptyset}=\frac{\sin 15.710}{265 / 22.5} \\
& \sin ^{\varnothing}=0.023
\end{aligned}
$$




$$
\emptyset=1.3180
$$

$\rightarrow$ Total thrust force acting on the connecting rod is given by

$$
\begin{aligned}
F Q & =\frac{F p}{\cos \theta} \\
& =\frac{25}{\cos 1.310^{\circ}} \\
F Q & =25.006 \mathrm{KN}
\end{aligned}
$$

$\rightarrow$ Now thrust force is split into two forces i.e tangential and radial

- Tangential force is given by $F T=F Q \times \sin (\theta+\emptyset)$

$$
F T=7.322 \mathrm{KN}
$$

- Radial Force is given by $F R=F Q \times \cos \left({ }^{\theta}+\emptyset\right.$ )

$$
F R=23.90 \mathrm{KN}
$$

D. Reaction and moment calculation -

$\rightarrow$ Reactions at the bearing 1 and 2 due to tangential force is given by

$$
\begin{aligned}
& H T 1=H T 2=\frac{\text { FT }}{2}=\frac{7.322}{2} \\
& H T 1=H T 2=3.661 \mathrm{KN}
\end{aligned}
$$

$\rightarrow$ Similarly, the reactions of the bearing $1 \& 2$ due to the radius force is given by

$$
\begin{aligned}
& H T 1=H T 2=\frac{\text { FR }}{2}=\frac{23.90}{2} \\
& H T 1=H T 2=11.95 \mathrm{KN}
\end{aligned}
$$

Twisting moment $=H T 1 \times$ cranl pin radius

$$
=3.661 \times 12.5
$$

Twisting moment $=45.67 \mathrm{KN}-\mathrm{mm}$

$$
\begin{aligned}
& \text { Moment at the center of crankshaft } \\
& M C=H R I \times d \\
& M C=537.75 K N-M M
\end{aligned}
$$


E. Stress calculation -

WKT, Von-misses' stresses induced in the crank due to loading is given by

$M e q=\sqrt{(K f+M C)^{2}+\frac{3}{4} \times(K t+T C e q)^{2}}$

Where TCeq $=$ equalent twisting moment

$T C e q=\sqrt{(M C)^{2}+(T c)^{2}}$

$K b=$ stress due to bending (Additional stress)

$K c=$ Additional stress due to torsion

For simplification of the problem, we are not considering the Kb and Kc value for the present calculation

Therefore, $M e q=\sqrt{(M C)^{2}+\frac{3}{4} \times(T c)^{2}}$

$$
M e q=9.394 \times 105 \mathrm{~N}-\mathrm{mm}
$$

Therefore, equivalent von-misses stress is given by

$M e q=\frac{\pi}{32} \times d^{3} \times c \times$ oeq

Where $c=$ parametric constant $(C=0.56$ parametric constant value for 2 -cylinder crank shaft $)$

$$
\begin{aligned}
& \text { Therefore } \\
& \sigma v=107.27 \mathrm{~N} / \mathrm{mm} 2
\end{aligned}
$$

Where $^{\text {ov }}$ is equivalent Von-misses stress. 


\section{RESULT AND DISCUSSION}

Equivalent von misses stress:

The equivalent von misses stress plots of crankshaft under static load. The contours shows the minimum and maximum value is 0 and $105.57 \mathrm{Mpa}$ at the connecting rod junction the stress value which is less than the yield value of the defined material.

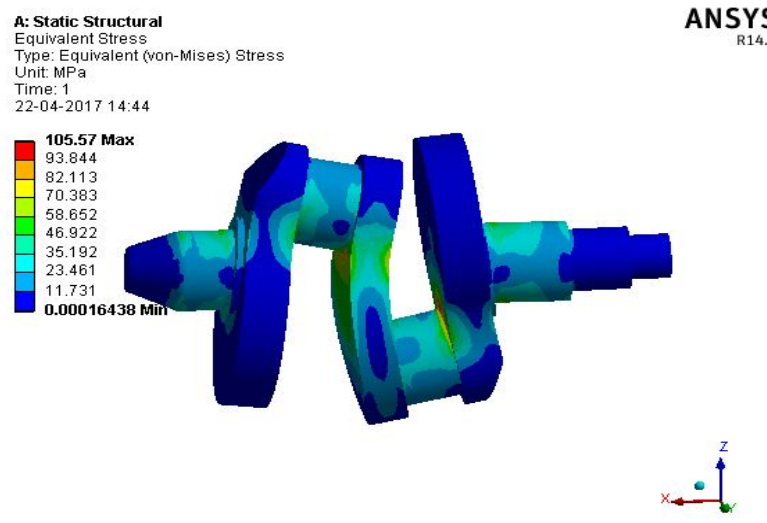

Figure 5. Von misses stress behaviour of body

Factor of safety (FOS):

The factor of safety of crankshaft under static load. The contours shows the minimum and maximum value is 0.81649 and 15 at the connecting rod junction.

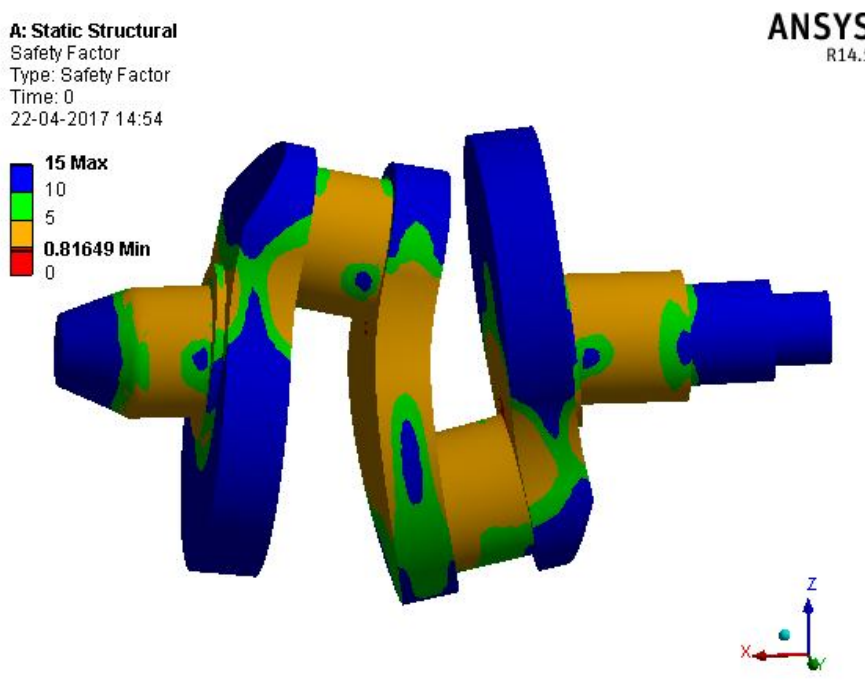

Figure 6. FOS of crankshaft 


\section{IV.CONCLUSION}

The equivalent von misses stress plots of crankshaft under static load. The contours shows the maximum value of $105.57 \mathrm{Mpa}$ at the connecting rod junction, from the stress analysis we can conclude that which is well below the yield strength of forged steel, i.e 250Mpa. Hence the crankshaft cylinder can withstand the load of $25 \mathrm{KN}$. The factor of safety of crankshaft under static load. The contours show the minimum value of 0.81649 at the connecting rod junction, the minimum fatigue life $3.119 \times 105$ for the crankshaft under static load at the connecting rod junction, maximum fatigue damage takes place at 3213.4 cycles under static load.

\section{REFERENCE}

[1] Alex.K.D, Arjun.P, Hassan.K , Vyshak.P, FEA APPROACH TO DYNAMIC ANALYSIS OF CRANKSHAFT , Proceedings of the "National Conference On Emerging Trends In Mechanical Engineering 2k13" 170 NCETIME - 2k13

[2] Mahesh L. Raotole, Prof. D. B. Sadaphale, Prof. J. R.Chaudhari, Prediction of Fatigue Life of Crank Shaft using S-N Approach International Journal of Emerging Technology and Advanced Engineering, ijetae, ISSN 2250-2459, Volume 3, Issue 2, February 2013

[3] Shin Han, Hoon Huh, Geum-Tai Han, Multi-body dynamic stress analysis of a crankshaft for V8 engine, KSAE 2008 Annual Conference pp.1-6 / KSAE08-A0006

[4] Ma Xingguo, You Xiaomei, Wen Bangchun, Multi-body Dynamics Simulation on Flexible Crankshaft System, 12th IFToMM World Congress, Besançon (France), June18-21, 2007

[5] Ashwani Kumar Singh, Praveen Kumar Singh, Akash KumarTripathi, Ajeet Yadav, Shyam Bihari lal, FEA of the crankshafts Design by using Ansys workbench For nickel chrome steel and structural steel, International Journal of Scientific \& Engineering Research, Volume 5, Issue 4, April-2014 1249 ISSN 2229-5518

[6] Zissimos P. Mourelatos, A crankshaft system model for structural dynamic analysis of internal combustion engines, Computers and structures 79 (2001) 2009-2027

[7] Boris B. Kosenok, Valeriy B. Balyakin, Study of the Dynamic Characteristics of a Two-Cylinder Internal Combustion Engine Using Vector Models, Procedia Engineering 106 ( 2015 ) 183 - 191

[8] Priya.D.Shah, Prof. Kiran.K.Bhabhor, Parametric Optimization of Four Cylinder Engine Crankshafts International Journal of Engineering Science Invention ISSN : 2319 - 6734, Volume 3 Issue 6, June 2014, PP.38-43

[9] Ravikumar katti,Vijayvitthal Illal, Lohitesh Jaga Kumar,Dr.Irfan G,"Evalution of structural parameters of two cylinder crankshaft using finite element method",IJIET volume 08, Issue 03,June 2017 